\title{
On Performing Experimental Studies on Transient States of Continuous-Flow Methanogenic Reactors
}

\author{
Allan J. DeLorme and Richard B. Kapuscinski* \\ Department of Civil Engineering, University of Michigan, \\ Ann Arbor, Michigan 48109
}

Accepted for publication December 20, 1988

\begin{abstract}
One approach to exploring the behavior of microbial cultures during transient conditions of unbalanced growth is to experimentally observe continuous-flow biological reactors which have been subjected to perturbations in the influent flowrate and/or concentration of growth-limiting substrate. Proper interpretation of such experiments requires that appropriate account be taken of reaction stoichiometry, the distribution and abundance of microbial populations within the reactor, and the nonideality of mixing and flow distribution in the reactor. These aspects of proper experimental design are particularly critical when the system of interest involves methanogenic consortia and is not a completely-mixed, suspended-growth reactor.
\end{abstract}

\section{INTRODUCTION}

The design of biochemical unit processes for wastewater treatment and water renovation has historically been based upon kinetic models which assume balanced microbial growth. This has generally been true for continuous-flow systems, for which steady-state models have been widely employed in design, but also for semicontinuous batch systems, which are inherently dynamic in their operation. Since wastewater flowrates and influent composition are temporally variable in most treatment systems, ${ }^{1}$ and since many biochemical unit processes involve a dynamic operation, ${ }^{2-5}$ there is a critical need to develop simple models of unbalanced, microbial growth that can be employed in the design and analysis of biochemical systems for wastewater treatment and water renovation. ${ }^{6}$ Several proposed dynamic models have been described and analyzed in recent years. ${ }^{7-10}$ However, rigorously collected experimental data are generally lacking to permit verification of the mechanistic basis of these models.

Recently, there has been renewed interest in the use of extremely anaerobic (methanogenic) biological processes for the treatment of industrial wastewaters. ${ }^{11-12}$ Exploitation

* To whom all correspondence should be addressed. Present address ENVIRON Corporation, 4350 North Fairfax Drive, Suite 300, Arlington. VA 22203. of this biotechnology for wastewater treatment has been stimulated in large measure by fundamental technical advances concerning the ecology of methanogenic consortia and the metabolism of the constituent populations. Establishing an appropriate model of unbalanced, dynamic growth of microbial populations in methanogenic consortia is particularly critical. The flowrates and composition of industrial wastewaters can be extremely variable. Moreover, one commonly perceived drawback of methanogenic systems is a reputation for instability when subjected to various operational changes. ${ }^{12-14}$ It is anticipated that fundamental technical advances concerning the dynamic behavior of anaerobic/ methanogenic bacteria could contribute to the development of appropriate modifications in design and operation that could lead to general improvements in the stability of methanogenic systems for wastewater treatment.

One way to gain information concerning transient microbial behavior is to temporarily perturb continuous-flow biological reactors. ${ }^{15}$ Recently there have appeared several published studies of this type involving methanogenic reactors. ${ }^{16-23}$ It is essential in such investigations to take appropriate account of reaction stoichiometry, the distribution and abundance of microbial populations within the reactor, and the nonideality of mixing and flow distribution in the reactor if rigorously correct interpretations concerning the dynamics of microbial activity are to be inferred. While this proposition would seem inarguable on the surface, ${ }^{24.25}$ it is the authors" contention that many published studies of this type do not take sufficient account of these factors. This seems particularly the case with investigations of methanogenic systems, which typically involve a consortium of metabolically distinct, but interacting, microbial populations, ${ }^{26}$ and for which gas production and composition can have several important, but sometimes subtle, effects on fluid mixing, biomass retention, and microbial kinetics. It is the intent of this article to elaborate upon this proposition and to cite several important considerations involved in performing and interpreting experimental investigations on continuous-flow anaerobic biological reactors that are subject to imposed transient conditions. 


\section{STOICHIOMETRY AND ECOLOGY OF METHANOGENIC PROCESSES}

The methanogenic treatment process relies on a balanced symbiotic relationship between interacting but metabolically distinct microbial populations. ${ }^{26}$ Organic polymers and high molecular weight fatty acids are converted to volatile fatty acid intermediates, principally propionic and butyric acids, by acidogenic bacteria. Acetic acid, which is acknowledged as the major intermediate in methanogenesis, ${ }^{27}$ is formed through the degradation of propionic and butyric acids (fermentative acetogenesis) and through the oxidation of hydrogen (respiratory acetogenesis); these two reactions appear to involve distinct acetogenic populations. ${ }^{13}$ Methane can only be formed by specific methanogenic bacteria which utilize acetic acid (acetoclastic methanogens) or hydrogen (hydrogen-oxidizing methanogens). ${ }^{26}$ Instability of extremely anaerobic treatment processes can result when this symbiotic balance between the methanogens and the acidogens is upset by excessive changes in organic loading or by differential inhibition of the populations by chemical agents.

According to several investigators ${ }^{28-30}$ the equation of propionate degradation may be written as follows:

$$
\begin{aligned}
\mathrm{CH}_{3} \mathrm{CH}_{2} \mathrm{COO}^{-}+3 \mathrm{H}_{2} \mathrm{O} \longrightarrow \mathrm{CH}_{3} \mathrm{COO}^{-} & +\mathrm{HCO}_{3}^{-} \\
& +\mathrm{H}^{+}+3 \mathrm{H}_{2}
\end{aligned}
$$

Kaspar and Wuhrmann ${ }^{28}$ have also shown that butyrate decomposes according to

$$
\begin{aligned}
\mathrm{CH}_{3} \mathrm{CH}_{2} \mathrm{CH}_{2} \mathrm{COO}^{-}+2 \mathrm{H}_{2} \mathrm{O} \longrightarrow 2 \mathrm{CH}_{3} \mathrm{COO}^{-} & \\
& +\mathrm{H}^{+}+2 \mathrm{H}_{2}
\end{aligned}
$$

In both cases molecular hydrogen is a product, the accumulation of which can inhibit further activity of the fermentative acetogens. Fortunately, two sinks exist for hydrogen: acetogenic respiration ${ }^{31}$

$$
4 \mathrm{H}_{2}-2 \mathrm{HCO}_{3}^{-}+\mathrm{H}^{+} \longrightarrow \mathrm{CH}_{3} \mathrm{COO}^{-}+4 \mathrm{H}_{2} \mathrm{O}
$$

and methanogenesis ${ }^{32}$

$$
4 \mathrm{H}_{2}+\mathrm{HCO}_{3}^{-} \longrightarrow \mathrm{CH}_{4}+2 \mathrm{H}_{2} \mathrm{O}+\mathrm{OH}^{-}
$$

The most commonly cited stoichiometric equation for acetoclastic methanogenesis is as follows: ${ }^{33.34}$

$$
\mathrm{CH}_{3} \mathrm{COO}^{-}+\mathrm{H}_{2} \mathrm{O} \longrightarrow \mathrm{HCO}_{3}^{-}+\mathrm{CH}_{4}
$$

Equations $11-15)$ represent the major reactions accounting for the breakdown of volatile fatty acids by acidogenic bacteria (eq. 11) and (2)), the oxidation of molecular hydrogen (eqs. (3) and (4)). and the microbial formation of methane (eqs. (4) and (5)). As written above each equation, neglects the formation of biomass; because of biomass formation, the observed product yields would be expected to be lower than the theoretical values predicted by these equations. ${ }^{24}$

Failure of the anaerobic digestion process is often associated with an upset of the symbiotic balance between the acidogenic and methanogenic populations. The potential specific growth rates of the acidogenic populations are typically higher than those of methanogens. ${ }^{2+.26 .35}$ Hence, when the organic loading is increased to a methanogenic reactor, the expected, rapid responses include a suppression of $\mathrm{pH}$, an accumulation of volatile acids, an elevation of molecular hydrogen in the solution- and gas-phases, and an increase in the content of carbon dioxide in the offgas. ${ }^{17.21 .22 .36 .37}$ The total volumetric rate of gas production may also increase rapidly in response to a stimulus in organic loading, but this phenomenon is not necessarily attributable to methane production. ${ }^{17,37}$ If the increase in loading is of sufficient magnitude and duration, a "stuck" digester can result. ${ }^{14.36 .37}$ Such a condition is usually associated with an accumulation of low-molecular weight organic acids, a drop in $\mathrm{pH}$, and elevated levels of gaseous hydrogen in the off-gas. ${ }^{16.23}$ Each of these changes appears to be capable of inhibiting at least one reaction or microbial group in the anaerobic treatment process. So. for instance, accumulation of acetic acid can inhibit the fermentation of propionic acid ${ }^{28}$ and may inhibit the grow th of acetoclastic methanogens. ${ }^{36.37}$ The sensitivity of methanogens to changes in $\mathrm{pH}$ is well known. ${ }^{24.38}$ Finally, the accumulation of hydrogen can inhibit acetogenesis from propionic and butyric acid ${ }^{13.28}$ and may regulate the pathways and kinetics of methanogenesis. ${ }^{13.33 .34 .39}$

\section{REACTOR DYNAMICS}

It is well established that the flow distribution and mixing characteristics can exhibit a substantial impact on the performance of biological reactors for water and wastewater treatment. ${ }^{24,25,40-42}$ So, for instance, changes in reactor geometry, the placement and configuration of inlets and outlets, and, in the case of biofilm processes, the placement and choice of support medium can greatly influence the extent of treatment that is achieved under steady-state conditions. ${ }^{40-43}$ What is less widely recognized is that the presence of flocculent biomass or biofilms can greatly influence fluid mixing and distribution and can complicate the interpretation of tracer studies for establishing the true residence time distribution (RTD) in a biological reactor. That is, the apparent residence time distribution of a biologically active reactor can differ from the RTD in the absence of biomass. ${ }^{25.40}$ This discrepancy can arise from short-circuiting and "dead spaces" attributable to the presence of thick masses of flocculent cells at the inlet of an up-flow reactor $^{41.42 .44}$ and from the exo-diffusion of tracer from flocculent or attached biomass, which can increase the apparent mean retention time and the apparent axial, dispersion coefficient. $^{45.46}$ In anaerobic processes, the production of gas can also influence fluid mixing and flow distribution. For instance, Bolle et al. ${ }^{44}$ found that the relative sizes of the sludge bed and the sludge blanket and the extent of shortcircuiting in an upflow anaerobic sludge blanket reactor were dependent upon the production rate of gas and the apparent rise velocity of gas bubbles. Inasmuch as gas production may increase rapidly as a response to a sudden increase in the organic loading to a continuous-flow reac- 
tor, one might expect the impact of biomass on flow distribution and fluid mixing would be most significant during transient conditions. The impact of these biomass-associated phenomena would also appear to be system-specific, so that the actual fluid RTD may not be identical in similar bioreactors of different scale and geometry. Only in the instance where the actual RTD is well-characterized will it be possible, in general, to make inferences about the dynamics of microbial growth from experimental studies on continuous-flow reactors that are subjected to imposed, transient conditions.

\section{BIOMASS ABUNDANCE AND DISTRIBUTION}

It would seem axiomatic that determination of biomass abundance and distribution would be necessary in any study of biological reactors in order to fully characterize the system of interest. Nevertheless, it is fairly common to see studies in which the existence of steady-state conditions in a continuous-flow, biological reactor is inferred solely from measurements of residual substrate concentration(s). In contrast, it is expected that for a period after the residual substrate concentration appears to have stabilized biomass may continue to accumulate until the rates of growth, attrition, and decay come into balance. ${ }^{47}$ In reactors with spatial gradients, the distribution of biomass could also change without substantially influencing the effluent concentration of residual substrate. Slow shifts in the predominant population(s) have also been observed in mixed-culture, continuousflow systems that evidence constant substrate removal over a long period.

The attrition via the effluent of dispersed cells and buoyant flocs and films can represent, for many continuousflow, biological reactors, a major cause of biomass loss. In instances where the intrinsic maximum specific growth rate of the requisite microbial population(s) is small, such attrition can also impair overall removal of soluble substrates. For example, Bolle et al. ${ }^{47}$ observed in their mathematical analysis of the up-flow anaerobic sludge blanket (UASB) process that in certain instances clarification at the outlet would need to be nearly perfect to prevent the washout of methanogenic bacteria. Hence, it is valuable in interpreting the results of experimental studies on continuous-flow biological reactors to have data concerning biomass attrition and retention. Nevertheless, many published studies lack data which would permit estimation of biomass loss. The unavailability of such data precludes calculation of the mean cell retention time, a parameter that is widely employed in the design and analysis of continuous-flow, biological reactors for wastewater treatment. ${ }^{24}$ Information on biomass attrition is particularly important in the analysis and interpretation of experimental studies of transient bioreactors, since sudden changes in influent flowrate or substrate concentration(s) can exacerbate biofilm sloughing or contribute to a deterioration of settling behavior. ${ }^{17.20 .22}$

\section{DISCUSSION}

Bhatia et al. ${ }^{18.19}$ reported experimental and theoretical research on an upflow anaerobic sludge blanket reactor (UASB), which received a soluble feed consisting of butyric, propionic, and acetic acids. Their reports include data pertinent to the transient behavior of methanogenic up-flow sludge blanket reactors. However, it is not apparent that the flow distribution, fluid mixing, and the distribution, abundance, and attrition of biomass were well-characterized in their study. Consequently, we believe that several critical conclusions discussed in these articles are not fully supportable by the reported data. Since the UASB process is receiving great attention for industrial wastewater treatment. ${ }^{12.47-50}$ we believe that it is imperative that these issues be adequately addressed.

Bhatia et al. ${ }^{18}$ reported data concerning the removal in a lab-scale UASB of acetic, propionic, and butyric acids, when this reactor was subjected to changes in influent concentration of one of the substrates or to changes in flow. For the experiments in which the influent concentration of a single acid was increased, the results generally suggest an ability of the accumulated biomass to rapidly transform the excess substrate. It was reported that an immediate increase in gas production was a typical response to substrate step-ups. In certain cases, an increase in the effluent concentration of one or both of the other acids was associated with a step-up in the influent concentration of a single volatile fatty acid. Data on individual experiments on transient behavior following a flowrate step-up were not reported. However, data on substrate removal during the apparently steady-state period after flowrate step-ups and step-downs were reported. From these data, the following inferences were made: ${ }^{18}$

- the sludge bed of the lab-scale reactor behaved as a CFSTR

- propionic acid inhibits acetoclastic methanogenesis

- steady-state substrate removal in UASBs will exhibit hysteresis

- methane production and cell growth by acetoclastic methanogens are uncoupled

Each of these conclusions is plausible, each to a different degree. However, in each case we believe that the reported data are insufficient to support the claim and to eliminate other explanations of the observed behavior.

The conclusion that the sludge bed behaved as a CFSTR was apparently based upon the frequent observation that the bulk of the elevated substrate influx was removed after a shiftup in the influent concentration. For instance, the effluent concentration of acetate increased from approximately $0.12 \mathrm{mM}(7 \mathrm{~g} / \mathrm{cu} \mathrm{m})$ to a peak of approximately $0.35 \mathrm{mM}(21 \mathrm{~g} / \mathrm{cu} \mathrm{m})$ following a step-up in the influent concentration from $10 \mathrm{mM}(600 \mathrm{~g} / \mathrm{cu} \mathrm{m})$ to $15 \mathrm{mM}$ $(900 \mathrm{~g} / \mathrm{cu} \mathrm{m})$ for a period of $12 \mathrm{~h}$ when the flowrate was $1.0 \mathrm{~L} / \mathrm{h}$. Since the acetoclastic methanogens are recognized to have slow, intrinsic maximum specific growth rates, the authors appear to imply that the reactor must be 
well-mixed to have dampened the substrate shock load to the extent that it did. However, the RTD of the lab-scale UASB was not reported. This is particularly troublesome since such studies on lab-scale and pilot-scale UASB reactors do not support the authors conclusion and, in fact, suggest that fluid mixing in UASBs can be quite complex and highly nonideal and can be substantially influenced by gas production. ${ }^{48-50}$ On the other hand, the observed response of a "small" perturbation in the effluent concentration of acetate in response to a step-up in feed concentration is consistent with the concept of "available reaction potential," which has been observed with aerobic heterotrophic consortia. ${ }^{6.51 .52}$ This concept suggests that microbial cells have a capacity, albeit limited, to rapidly increase their specific assimilation rate in response to a sudden increase in the availability of substrate. While "available reaction potential" has not apparently been unequivocally demonstrated in extremely anaerobic bacteria, it represents a very plausible explanation of the observed results. However. in the absence of data to characterize fluid mixing, flow distribution, and biomass distribution and abundance. it is not possible to firmly substantiate any single explanation to the exclusion of others.

It was observed that the effluent concentration of acetate increased in response to a step-up in the influent concentration of propionic acid. On this basis, it was concluded that propionic acid inhibits acetoclastic methanogenesis. However, it would appear that the authors neglected to consider that acetic acid will be produced from fermentation of propionic acid (eq. (1)) and from acetogenic respiration (eq. (3)), using the molecular hydrogen produced from propionate (eq. (1)). Indeed, the authors explained a similar peak of acetic acid after a step-up of butyric acid by its production rather than inhibition of its consumption. Furthermore. other investigators ${ }^{53}$ did not observe inhibition of methanogenesis even at propionic acid concentrations as high as $6000 \mathrm{~g} / \mathrm{cu} \mathrm{m}$, a level which exceeds the influent concentration of propionic acid in the authors' experiments.

The authors apparently performed flowrate step-up and step-down experiments with the synthetic feed and reported hysteretic behavior for the steady-state utilization of acetic and propionic acids. They attributed the hysteresis to substrate inhibition controlling the reaction at high volatile acid concentrations. These observations would seem to suggest that UASB reactors might not return to the same initial condition upon relaxation of flow-rate step-ups.

As noted previously, the authors' experimental evidence does not completely support a conclusion of inhibition, at least for the case of propionic acid and acetoclastic methanogenesis. Moreover, alternative explanations for the apparently hysteretic behavior cannot be ruled out. In particular, it is plausible that during the series of flowrate step-up experiments biomass attrition via the effluent occurred and impacted the abundance of methanogens and propionic acid-utilizing fermenters to a greater extent than the butyric acid-utilizing acetogens. This hypothesis is given indirect support by the observations (1) that the residual concentrations of acetic and propionic acids at the higher flowrates were greater than those for butyric acid, (Figs. 10-12), (2) that the minimum cell residence times, associated with biomass washout, are greater for acetoclastic methanogenesis and acetogenesis from propionic acid than for fermentation of butyric acid, ${ }^{14}$ and (3) that the hysteretic behavior was observed only at the higher flowrates. Measurements of the distribution, abundance and attrition of the biomass would have helped to resolve the explanation for the apparent hysteresis. Biomass attrition would seem to be of particular importance in this case. Increases in the flowrate can stimulate biomass detachment and buoyancy associated with accelerated gas production, ${ }^{17,20-22}$ so that if the clarifier in a UASB is not well-designed, poor clarification and biomass retention can easily result. ${ }^{* *}$

The authors found that gas production rates responded almost instantaneously to step changes in the influent conditions. On this basis, they concluded that methane production and cell growth by acetoclastic methanogens are uncoupled. While it might be true that energy-producing methanogenesis and energy-consuming biosynthesis can become temporarily uncoupled during the early stages of a transient event, the authors do not present the necessary data to demonstrate unequivocally that this occurred. Data on biomass distribution and abundance are not reported, so that it is not possible to assess whether methanogens can rapidly increase their growth rate. Additionally, data on the composition of gas during transient conditions are not reported, so that it is not possible to attribute in each instance all of the excess gas production to methanogenesis. Indeed, a common observation in studies of anaerobic reactors is that the increase in gas production that results from a step-up in the influent concentration of propionic and butyric acids, or their precursors, is initially attributable to formation and stripping of carbon dioxide and molecular hydrogen. ${ }^{17.37}$

Bhatia et al. proposed a model of microbial methane formation from volatile fatty acids. ${ }^{19}$ Rate expressions were chosen and parameters calibrated to simulate the observed hysteretic behavior when the sludge blanket was represented as a CFSTR. Given the uncertainty in the actual flow dynamics in their lab-scale UASB and the ambiguities in the mechanistic explanation of several of their experimental observations, their calibrated model does not appear to be generally applicable for predicting or simulating microbial methane formation from volatile fatty acids.

\section{CONCLUSIONS}

The relatively scant amount of fundamental knowledge of the metabolism and ecology of anaerobic populations in methanogenic consortia makes it difficult to completely predict the response of methanogenic treatment reactors to sudden changes in the organic loading. Experimental investigations of such systems are not trivial exercises, since several distinct metabolic populations are involved and gas 
production can have important, yet subtle, impacts upon flow distribution, fluid mixing, and biomass attrition and distribution. Proper design and interpretation of such important experiments dictates that reaction stoichiometry, microbial ecology, reactor dynamics, and biomass abundance and attrition be fully considered and quantified.

\section{References}

1. Metcalf and Eddy, Inc., Wastewater Engineering: Treatment, Disposal, and Reuse, Second edition. (McGraw-Hill, New York, 1979).

2. B. Batchelor, J. Water Pollut. Control Fed., 54, 1493 (1982).

3. Y. Comeau, K. J. Hall, R. E. W. Hancock, and W. K. Oldham. Water Research, 20, 1511 (1986).

4. J. F. Manning, Jr. and R. L. Irvine, J. Water Pollut. Control Fed., $57,87(1985)$

5. J. Silverstein and E. D. Schroeder, J. Water Pollut. Control Fed., 55, 377 (1983).

6. G. T. Daigger and C. P. L. Grady, Jr., Water Research. 16, 365 (1982)

7. J. B. Busby and J. F. Andrews. J. Water Pollut. Control Fed., 47, 1055 (1975).

8. L. M. Chase, Biotechnol. Bioeng., 19, 1431 (1977).

9. R. C. Clifft and J. F. Andrews, J. Water Pollut. Control Fed., 53, 1219 (1981)

10. R. W. Dennis and R. L. Irvine, Water Research, 15, 1363 (1981).

11. L. van den Berg, Canad. J. Microbiol., 30, 975 (1984)

12. R. E. Speece, Environ. Sci. Technol., 17, 416A (1983).

13. S. R. Harper and F. G. Pohland, Biotechnol. Bioeng., 28, 585 (1986).

14. G. Parkin and W. F. Owen, J. Environ. Eng. (ASCE), 112, 867 (1986).

15. R. I. Matales, D. Y. Ryu, and T. Yasuda, Nature, 208, 263 (1965).

16. D. B. Archer, M. G. Hilton, P. Adams, and H. Wiecko, Biotechnol. Lett., 8, 197 (1986).

17. D. Barnes, P. J. Bliss, B. Grauer, and K. Robins, Environ. Technol. Lett., 6, 73 (1984).

18. D. Bhatia, W. R. Vieth, and K. Venkatasubramanian. Biotech. Bioeng.. 27, 1192 (1985).

19. D. Bhatia, W. R. Vieth, and K. Venkatasubramanian. Biotech. Bioeng., 27, 1199 (1985).

20. M. A. Bull, R. M. Sterritt, and J. N. Lester, Water Research, 17, 1563 (1983).

21. K. J. Kennedy and L. van den Berg, Water Research, 16, 1391 (1982).

22. K. J. Kennedy, M. Muzar, and G. H. Copp. Biotechnol Bioeng., 27, $86(1985)$

23. T. N. Whitmore, M. Lazzari, and D. Lloyd, Biotechnol. Lett.. 7, 283 (1985).

24. C. P. L. Grady, Jr., and H. C. Lim, Biological Wastewater Treatment. Theory and Applications. (Marcel Dekker, New York, 1980).
25. J. E. Bailey and D. F. Ollis, Biochemical Engineering Fundamentals. Second edition. (McGraw-Hill, New York, 1986).

26. R. A. Mah, Phil. Trans. Royal Soc., London B, 297, 599 (1982).

27. J. S. Jeris and P. L. McCarty, J. Water Pollut. Control Fed., 37, 178 (1965).

28. H. F. Kaspar and K. Wuhrmann, Microbial Ecol., 4, 241 (1978).

29. S. L. Neave and A. M. Buswell, J. Am. Chem. Soc., 52, 3308 (1930).

30. T. C. Stadtman and H. A. Barker, J. Bacteriol., 61, 81 (1951).

31. L. G. Ljungdahl, Annu, Rev. Microbiol., 40, 415 (1986).

32. J. G. Zeikus, P. J. Weimer, D. R. Nelson, and L. Daniels, Arch. Microbiol., 104, 129 (1975).

33. M. R. Smith and R. A. Mah, Appl. Environ. Microbiol., 36, 870 (1978).

34. R. A. Mah, M. R. Smith, and L. Baresi, Appl. Environ. Microbiol., 35, 1174 (1978).

35. W. Gujer and A. J. B. Zehnder, Water Sci. Technol., 15, 127 (1983).

36. A. Dalla Torre and G. Stephanopolous. Biotechnol. Bioeng., 28, 1106 (1986)

37. S. P. Graef and J.F. Andrews, J. Water Pollut. Control Fed., 46, 666 (1974).

38. R. H. Heyes and R. J. Hall, Biotechnol. Lett., 3, 431 (1981).

39. T. J. Ferguson and R. A. Mah, Appl. Environ. Microbiol., 46, 348 (1983).

40. R. A. Ferrara and D. R. F. Harleman, J. Env. Eng. Div., ASCE, 107, 817 (1981).

41. R. Samson, L. van den Berg, and K. J. Kennedy, Biotechnol. Bioeng., 27, 10 (1985)

42. R. Samson and K. J. Kennedy, J. Biotechnol., 2, 95 (1985).

43. J. C. Young and M. F. Dahab, Water Sci. Technol., 15, 369 (1983).

44. W. L. Bolle, J. van Breugel, G. C. van Eybergen, N. W. F. Kossen, and R. J. Zoetemeyer, Biotech. Bioeng., 28, 1615 (1986).

45. M. Riemer, G. Holm Kristensen, and P. Harremoes, Water Research, 14, 949 (1980).

46. D. K. Stevens, P. M. Berthouex, and T. W. Chapman, Water Re search, 20, 369 (1986).

47. W. L. Bolle, J. van Breugel, G. C. van Eybergen, N. W. F. Kossen, and W. van Gils, Biotech. Bioeng., 28, 1621 (1986).

48. P. M. Heertjes and L. J. Kuijvenhoven, Biotechnol. Bioeng.. 24, 443 (1982).

49. P. M. Heertjes and R. R. Van Der Meer, Biotechnol. Bioeng., 20, 1577 (1978)

50. R. R. Van Der Meer and P.M. Heertjes, Biotechnol. Bioeng., 25, 2531 (1983).

51. J. S. Cech and J. Chuboda, Water Research, 17, 659 (1983).

52. E. Van den Eynde, L. Vriens, M. Wynants, and H. Verachtert, Europ J. Appl. Microbiol. Biotechnol., 19, 44 (1983).

53. I. J. Kugelman and K. K. Chin, Adv. Chem. Ser. 105, 55 (1971). 